\title{
Analysis of "care" and “justice” involved in moral reasoning of nurse based on the Gilligan theory: A literature review using the Gilligan's protocol
}

\author{
Kayoko Tsunematsu ${ }^{1,2}$, Atsushi Asai ${ }^{2}$ \\ ${ }^{1}$ Department of Nursing, Faculty of Health Science, Kumamoto Health Science University, Kumamoto, Japan \\ ${ }^{2}$ Department of Bioethics, Kumamoto University Graduate School of Medical Science, Kumamoto, Japan \\ Email: buzzurg2000@aqr.bbiq.jp
}

Received 4 December 2013; revised 5 January 2014; accepted 26 January 2014

Copyright (C) 2014 Kayoko Tsunematsu, Atsushi Asai. This is an open access article distributed under the Creative Commons Attribution License, which permits unrestricted use, distribution, and reproduction in any medium, provided the original work is properly cited. In accordance of the Creative Commons Attribution License all Copyrights (C) 2014 are reserved for SCIRP and the owner of the intellectual property Kayoko Tsunematsu, Atsushi Asai. All Copyright (C) 2014 are guarded by law and by SCIRP as a guardian.

\section{ABSTRACT}

The majority of research on the moral development of nurses is in line with Kohlberg's theory. However, Gilligan noted that care and justice perspectives coexist in moral conflict, and during the growth process, each complements each other and promotes moral development and maturation. Chally, referring to Gilligan's theory, which has the perspective of relationship-focused care, argued that the moral development of nurses should be considered from both care and justice perspectives. In this paper, we analyzed publications that used Gilligan protocol to conduct research on moral conflicts experienced by nurses. Given the importance of care and justice perspectives in moral reasoning, Gilligan's theory, which incorporates both perspectives, is useful for analyzing moral reasoning in nurses. Our analysis suggests that attachment and connections based on relationships with patients and self-care are essential elements of care, and self-care is important in moral decision making. The inequality between nurse and physician roles was an issue raised with the justice perspective. Since nurses' roles are strongly influenced by their affection toward and connections with their patients, it is important not to overemphasize either perspective.

\section{KEYWORDS}

Care; Justice; Nurse; Moral Perspective; Moral Reasoning

\section{INTRODUCTION}

According to Gilligan [1], women's construction of the moral problem as a problem of care and responsibility in relationships rather than as one of rights and rules ties the development of their moral thinking to changes in their understanding of responsibility and relationships, just as the conception of morality as justice ties development to the logic of equality and reciprocity. With moral development, humans began to express the care and responsibility they acquired as what Gilligan calls the ethics of care and responsibility. Once men came to judge and respect their own and another's argument equally, this was termed the ethics of rights, which is tantamount to the ethics of justice. Gilligan [1] also noted that the counterpoint of identity and intimacy that marks the time between childhood and adulthood is articulated through two different moralities whose complementarity is the discovery of maturity. That is, care and justice perspectives coexist in conflict, and during the growth process, each complements each other and promotes moral development and maturation.

Kuhse [2] stated that a partialist ethics of care can never account for the whole of ethics, an adequate ethics needs impartiality as well as care. Ethics can be considered from the care and justice perspectives, and through these perspectives, proper judgments can be made.

Care has numerous definitions, but can be broadly divided into behavior, posture and attitude. In the nursing field, the act of nursing itself is often referred to as care. In care ethics, however, the nuance of posture and attitude is stronger. Gilligan [1] stated that a progressively more adequate understanding of the psychology of human relationships informs the development of an ethic of care, and Noddings [3] noted that the essential elements of caring are located in the relation between the onecaring and the cared for. Nursing finds its basis in the 
relationship between a patient and a nurse who provides assistance. The essence of nursing is care, and care ethics serves as an important perspective. The ethics of justice refers to nurses maintaining fairness in order to preserve the patient's best interests, and abiding by universal duties and principles. Without the justice perspective, nurses may be influenced by subjective judgments. Thus, the ethics of justice also plays an important role in nursing. Both care and justice perspectives help nurses in ethical decision making.

The majority of research on the moral development of nurses is in line with Kohlberg's theory [4,5]. According to Chally [4], Rest's Defining Issues Test (DIT) and Ketefian's Judgment About Nursing Decisions (JAND) are widely used in such studies. These studies used Kohlberg's theory to clarify the educational content needed to increase the level of moral reasoning and nursing abilities. However, Chally [6], referring to Gilligan's theory, which has the perspective of relationship-focused care, argued that the moral development of nurses should be considered from both care and justice perspective. Moreover, Casterlé [7] criticized the lack of the care perspective in Kohlberg's theory, emphasized the need to include the care perspective in nursing, and proposed a conceptual structure that added the care perspective to Kohlberg's theory. Nonetheless, recent studies based on moral development theories have relied on Kohlberg's theory more frequently than Gilligan's theory. Studies using Gilligan protocol (hereafter, "GP”) indicate the existence of care and justice perspectives in moral reasoning by nurses, but such studies are few in number [8-11].
The aim of this study was to analyze previous studies that used GP in order to establish a foundation for incorporating the care and justice perspectives in analytical studies of moral reasoning in nurses.

\section{OBJECTIVE}

This study aimed to assess the usefulness of Gilligan's theory in the analysis of moral reasoning in nurses.

\section{METHODS}

We analyzed publications that used GP to conduct research on moral conflicts experienced by nurses. Inclusion criteria were publications which assessed moral conflicts experienced by nurses and used a categorization table for care and justice perspectives based on GP. Content analysis was performed on the details of care and justice perspectives extracted from these publications. We also summarized the views of the authors of each publication using direct quotes.

\section{RESULTS}

\subsection{Target Publications}

Based on a PubMed search, we identified six publications that used GP, 5 of which targeted nurses, and 3 of which used a categorization table for care and justice perspectives (Table 1). All publications surveyed the decision making of nurses in situations involving moral conflict. The studies by Chally [10] and Millette [9] used a qualitative and descriptive design, whereas Chally's 1995 study [11] statistically analyzed qualitative data.

Table 1. A summary of the nursing research using the protocol of Gilligan.

\begin{tabular}{|c|c|c|c|c|}
\hline Author & Purpose of study & Sample & Data collection & Data Analysis \\
\hline $\begin{array}{l}\text { Chally, P.S. } \\
\text { (1992) }\end{array}$ & $\begin{array}{l}\text { To obtain the information } \\
\text { about the viewpoint at } \\
\text { moral decision making } \\
\text { of the NICU nurse }\end{array}$ & $\begin{array}{l}26 \text { NICU } \\
\text { nurses }\end{array}$ & $\begin{array}{l}\text { Semi-structured interviews } \\
12 \text { open-ended interviews question } \\
\text { based on "the Real life Moral } \\
\text { Conflict and Choice Interview } \\
\text { Guide" by Gilligan et al. }\end{array}$ & $\begin{array}{l}\text { The interview data transcripted, the transcript } \\
\text { data was read in a different viewpoint five times. } \\
\text { The moral decision making is interpreted from } \\
\text { care, justice, combined care and justice, the number } \\
\text { of other perspectives. }\end{array}$ \\
\hline $\begin{array}{l}\text { Chally, P.S. } \\
\text { (1995) }\end{array}$ & $\begin{array}{l}\text { To compare and contrast the } \\
\text { perspective used by nurses } \\
\text { working in NICU and ICU } \\
\text { when making moral decision }\end{array}$ & $\begin{array}{l}26 \text { NICU } \\
\text { nurses, } \\
25 \text { ICU } \\
\text { nurses } \\
51 \text { nurses } \\
\text { in total }\end{array}$ & $\begin{array}{l}\text { Semi-structured interviews } \\
12 \text { open-ended interviews question } \\
\text { based on "the Real life Moral } \\
\text { Conflict and Choice Interview } \\
\text { Guide" by Gilligan et al. }\end{array}$ & $\begin{array}{l}\text { The interview data transcripted, the transcript } \\
\text { data was read in a different viewpoint five times. } \\
\text { The moral decision making is interpreted from } \\
\text { care, justice, combined care and justice, the } \\
\text { number of other perspectives. } \\
\text { It is compared with the care about a small } \\
\text { category of the justice according to a place } \\
\text { of employment by a chi square test. }\end{array}$ \\
\hline $\begin{array}{l}\text { Millette, B.E. } \\
\text { (1994.) }\end{array}$ & $\begin{array}{l}\text { To clarify the moral } \\
\text { decision making process } \\
\text { of the actual nursing } \\
\text { situations }\end{array}$ & 24 nurses & $\begin{array}{l}\text { Semi-structured interviews } \\
\text { an established method by } \\
\text { Gilligan et al. }\end{array}$ & $\begin{array}{l}\text { The content analysis that was defined by } \\
\text { Gilligan et al. } \\
\text { The interview data transcripted, the transcript data } \\
\text { was read in a different viewpoint four times. } \\
\text { The investigator determined which care and justice } \\
\text { erspectives were present in the narrative. } \\
\text { A determination was made as to which orientation } \\
\text { was in alignment with statements that depicted } \\
\text { the sense of self. }\end{array}$ \\
\hline
\end{tabular}


All publications included semi-structured interviews based on the 11-item self-administered questionnaire from Gilligan's Real Life Moral Conflict and Choice Interview Guide (GP). Chally [10,11] included some additional questions which addressed conflicts and solutions, as well as those related to the evaluation of choices made. Content analysis was performed in the studies by Chally [10,11] and Millette [9] based on Gilligan's reading guide, interview contents were transcribed, and transcribed data were read from four different viewpoints. The first reading was performed to understand the conflict as a whole, the second reading focused on the thought process and behavior of the person who had the conflict, and the third and fourth readings were from the viewpoints of care and justice, respectively. Chally $[10,11]$, also included a fifth reading in order to address perspectives other than those of care and justice. Furthermore, Chally, as well as others [9], and categorized the moral decision making of nurses based on whether the care or justice perspective dominated.

\section{2. "Care" and "Justice"}

Nurses' decision making in moral conflicts was categorized based on the dominating perspective. Most nurses used the care perspective, followed by those who used a combined care and justice perspective, and lastly the justice perspective (Table 2). The specific details of care and justice perspectives are provided in Table 3 .

Chally [10] generated nursing profession-specific categories based on Gilligan's categorization of care and justice because Gilligan's categorization related to personal conflicts among young individuals, and did not focus on the occupational conflicts experienced by nurses. Gilligan's categories that were unrelated to nursing were removed. Chally [10] identified the following as care concepts from moral conflicts experienced by NICU nurses: not hurting, welfare of others, attachment and connection, appreciation of differences, and care of self.

According to Chally [10], all the nurses expressed an understanding of the care perspective.
Nurses discussed care orientation from the perspective of not hurting. Care took the form of protecting the neonates from pain and hurt. Nurses expressed concern about the pain endured by their patients. [10]

The nurses' concerns about the welfare and others were expressed in two ways: present and future. First, the data suggested that the nurses were attuned to specific needs of the neonates, both physically and psychologically. Examples of this category of the care perspective reveal the nursing expertise of those interviewed: "[As] the nurse who has been at the bedside for 12 hours... you have a much better idea than the physician of what's going on with the baby." Second, nurses distinctly stated concerns about the neonates' and parents' futures if the neonates survived. The nurse expressed concern about the quality of life that might be experienced by neonates who were discharged from the unit [10].

The term attachment describes a relationship between two or more people based on love and acceptance. The term connection is defined as responding to others on the others' term. Attachment and connection emerged as important components of the care perspective. Nurses expressed attachment and connection to neonates, parents, and colleagues [10].

Though not as pervasive as other aspects of care, an appreciation of differences between people was apparent in the nurses' descriptions of moral dilemmas. The nurses articulated attempts to understand others' ways of behaving, their feelings, and their thoughts [10].

Care of self was the final category identified by the nurses. The nurse described how they were able to continue working in the NICU despite the heavy emotional toll. They described a process of detaching or separating from their patients. This served a protective function. Another way the nurses cited they cared for the self was by taking pride in the quality of nursing care given. The nurses described being comforted by the knowledge that they did their best [10].

Similar to the care categories discussed above, Chally [10] identified the following justice categories: legal issues, rights, rules, obligations and commitments, societal

Table 2. Care and justice taxonomy result $(\mathrm{N}=101)$.

\begin{tabular}{|c|c|c|c|c|c|c|c|}
\hline \multirow[t]{2}{*}{ Author } & & \multicolumn{2}{|c|}{ Care predominance } & \multicolumn{2}{|c|}{ Justice predominance } & \multicolumn{2}{|c|}{ Combined care and justice } \\
\hline & & No & $\%$ & No & $\%$ & No & $\%$ \\
\hline Chally, P.S. (1992) & NICU & 17 & 65 & 3 & 12 & 6 & 23 \\
\hline \multirow{2}{*}{ Chally, P.S. (1995) } & NICU & 17 & 65 & 3 & 12 & 6 & 23 \\
\hline & ICU & 15 & 60 & 3 & 12 & 7 & 28 \\
\hline Millette, B.E. (1994.) & & 17 & 71 & 6 & 25 & 1 & 4 \\
\hline total & & 66 & 65 & 15 & 15 & 20 & 19 \\
\hline
\end{tabular}


Table 3. Contents of care and justice obtained from the study.

\begin{tabular}{|c|c|c|}
\hline Author & Care perspective & Justice perspective \\
\hline $\begin{array}{l}\text { Chally, P.S. } \\
\text { (1992) }\end{array}$ & $\begin{array}{l}\text { Not hurting } \\
\text { It took the form of protecting the neonates from pain and hurt. } \\
\text { The pain that the patient endure. (p.477) } \\
\text { Welfare of others } \\
\text { It was described from present and future. } \\
\text { In present the data suggested that the nurses were attuned to } \\
\text { the specific needs of neonates. In future, the data suggested } \\
\text { that nurses stated concerned about the neonates' and parents' } \\
\text { futures if the neonates survived by cure. (p.477) } \\
\text { Attachment and connection } \\
\text { The term attachment describes relationship between two or } \\
\text { more people based on love and acceptance, the term connection } \\
\text { defined as responding to others on the others' terms. } \\
\text { Important components of the care perspective } \\
\text { Nurses expressed these terms to neonates, parents and } \\
\text { colleagues. (p.477) } \\
\text { Appreciation of differences } \\
\text { Attempts to understand other' ways of behaving, their feelings, } \\
\text { and their thoughts. } \\
\text { An attempt to understand the other's experiences. (p.477) } \\
\text { Care of self } \\
\text { Protecting self as thinking how nurses were able to continue } \\
\text { working in the NICU despite of the heavy emotional toll. } \\
\text { Taking pride in the quality of nursing care given being } \\
\text { comforted by the knowledge that they did best. (p.477) }\end{array}$ & $\begin{array}{l}\text { Legal issues } \\
\text { Correct behavior was determined by fixed rules and the } \\
\text { maintenance of social order through the legal system. (p.478) } \\
\text { Rights } \\
\text { It was similar to laws, the process of making moral decisions } \\
\text { based on person's rights maintained social order through fixed } \\
\text { principles. (p.478) } \\
\text { Rules } \\
\text { Coping with moral dilemmas by following orders or } \\
\text { protocols.(p.478) } \\
\text { Obligations and commitments } \\
\text { Obligating to cure for physicians, obligating for profession } \\
\text { Te unit serving as the research setting was located in a } \\
\text { teaching hospital where residents needed to learn certain } \\
\text { procedures and techniques. (p.479) } \\
\text { Societal concerns } \\
\text { Concerns about the state and society. } \\
\text { Standards used to make decisions about high-risk neonates } \\
\text { have not been accepted as “right” by all members of society. } \\
\text { (p.479) } \\
\text { Roles } \\
\text { The inequality of roles between nurses and physicians. } \\
\text { (p.479) }\end{array}$ \\
\hline $\begin{array}{l}\text { Chally, P.S. } \\
\text { (1995) }\end{array}$ & $\begin{array}{l}\text { Five concepts of care by Chally (1992) } \\
\text { Not hurting } \\
\text { This category was the only statistically significant (p < } 0.001 \\
\text { by a chi square test) variation between NICU and ICU nurses. } \\
\text { Seventy-seven percent of the NICU nurses, but only } 16 \% \text { ICU } \\
\text { nurses, discussed protecting the patient from pain and hurt. } \\
\text { (p.121) } \\
\text { Attachment and connection } \\
\text { Both NICU and ICU nurses used this category. This category } \\
\text { defined by the author as a relationship between two or more } \\
\text { people based on love and acceptance and reacting to others } \\
\text { based on their own situation. (p.121) } \\
\text { Care of self } \\
\text { The significance of self-care was documented in this research } \\
\text { as the category remains an important component of the care } \\
\text { taxonomy. } \\
\text { If nurses learned the importance of caring for self, they may } \\
\text { find themselves less stressed and likely to burnout, either } \\
\text { physically or emotionally. (p.123) }\end{array}$ & $\begin{array}{l}\text { Six concepts of justice by Chally (1992) } \\
\text { Roles } \\
\text { The inequality of roles between nurses and physicians. } \\
\text { Thought of family related to medical care for the terminally } \\
\text { ill patient turned over by thought of the physician. The nurse } \\
\text { expressed her frustration at how the original physician was } \\
\text { unable to "care". } \\
\text { If nurse/physician collaboration were to increase, it seems } \\
\text { plausible that concerns over role inequities would decrease. } \\
\text { (p.123) }\end{array}$ \\
\hline $\begin{array}{l}\text { Millette, B.E. } \\
\text { (1994.) }\end{array}$ & $\begin{array}{l}\text { A pure care orientation } \\
\text { The statements describing the narrator's sense of self aligned } \\
\text { with statements that referred to connections and relationships. } \\
\text { There were many references to relationships and connections } \\
\text { to both the patient and his family, as well as references to } \\
\text { relationships to fellow staff members. Statements were made } \\
\text { indicating that a stronger relationship existed between this } \\
\text { young nurse and the client and his family than between her } \\
\text { and other members of the staff. (p.669) } \\
\text { A mostly caring orientation } \\
\text { A subject emphasized relational aspects in her discussion. } \\
\text { In the narrative, She referred to her relationship to elderly } \\
\text { woman and expressed admiration and affection for her. } \\
\text { (p.666) }\end{array}$ & $\begin{array}{l}\text { A mostly Justice orientation } \\
\text { A subject is seen to refer frequently to principles and rights. } \\
\text { The nurse knew the fact to record false content. The nurse } \\
\text { said about self ,’I had this sense of pure mission, white horse } \\
\text { and all”, and said she was committed to "honesty and integrity." } \\
\text { The nurse stated that patient care was compromised to the point } \\
\text { where my military career really should have been secondary. } \\
\text { Power in the formal chain of command a nurse relied on first } \\
\text { initially prevented resolution of the problem, power from the } \\
\text { informal network finally initiated the process of resolution } \\
\text { and triggered the formal network. (p.668) }\end{array}$ \\
\hline
\end{tabular}

concerns, and roles. The justice perspective was found to be used far less often that the care perspective when NICU nurses made moral decisions. Only three nurses (12\%) interviewed made moral decisions by aligning self with justice. [10]

Nurses described the justice perspective when they referred to the legal issues of a moral dilemma. For these nurses, correct behavior seemed to be determined by 
fixed rules and the maintenance of social order through the legal system [10].

Nurses described the justice orientation from the perspective of rights. For them, rights were similar to laws. The process of making moral decisions based on a person's rights maintained social order through fixed principles. One nurse said, "This is a human being here who also has a right to die, a right to peace.” [10].

Nurses discussed the justice orientation from the rules perspective. At times, the nurses indicated that they coped with moral dilemmas by following orders or protocols and by not thinking about the situation [10].

The understanding of justice as a set of obligations and commitments was described by the nurses when they discussed physicians' understanding of dilemmas. They suggested that physicians were obligated to cure. Another aspect of the justice category was that the unit serving as the research setting was located in a teaching hospital where residents needed to learn certain procedures and techniques. A commitment to educate health-care providers was a problem in some situations [10].

Nurses also discussed the justice orientation from the perspective of societal concerns. Five nurses voiced concerns about US society in general. They suggested that standards used to make decisions about high risk neonates have not been accepted as "right" by all members of society, and they questioned whether the laws need to be altered [10].

A common theme throughout the interviews was the inequality of roles between nurses and physicians. The nurses were distressed by role constraints they identified as results of this inequality [10].

Using the various care and justice categories [10], Chally [11] compared ICU and NICU nurses. The care taxonomy described by Chally (1992) remained valid for the care perspective described by adult intensive care nurses. The various methods of describing care, identified as care taxonomy, were all described by the adult intensive care nurses as they discussed dilemmas experienced in professional practice. All nurses, both neonatal and adult intensive care, used the attachment and connection category as they described moral dilemmas [11].

Not hurting was used more with NICU nurses than with ICU nurses. An appreciable difference in the frequency of the use of the category entitled "not hurting" was the only statistically significant $(p<0.001$ by chisquare test) variation between neonatal and adult intensive care nurses [11].

The significance of self-care was documented in this research as the category remains an important component of the care taxonomy [11]. If nurses learned the importance of caring for self, they may find themselves less stressed and less likely to burnout, either physically or emotionally [11].
A major component of the justice taxonomy as discussed by nurses interviewed was roles. Nurses frequently discussed moral dilemmas related to the inequality of roles between nurses and physicians [11]. For example, take the situation in which an artificial respirator attached to a terminal stage patient is removed by a physician with the family's consent, and the patient dies subsequently. In this particular situation, nurses expressed frustration of not being able to provide sufficient care to the patient because the family's thoughts changed rapidly based on the physician's thoughts. In view of this, Chally [11] indicated that role inequalities would decrease if nurses and physicians understood each other and increased nurse/physician collaborations.

Millette [9] categorized interview results based on the degree of predominance of the care and justice orientations, and presented and analyzed the details of representative cases. In the pure care orientation narrative, the caring perspective was the only perspective that was evident [9]. Referenced were connections and relationships with the patient and the patient's family. In the mostly caring orientation narrative, the nurse related the characteristics of her relationship with the elderly patient, and admiration and affection toward the patient were emphasized. In the mostly justice orientation narrative, the nurse frequently referred to principles and rights. At the military hospital ward where she worked, the nurse found out that an enlisted patient did not have his body temperature taken, but rather a false temperature was recorded. Even upon consulting the patient's superior, the head nurse, and the chief nurse of the ward, the problem could not be resolved. The problem was successfully resolved when the enlisted patient conferred with the previous chief nurse of the ward. The nurse said, "I had this sense of pure mission, white horse and all", and said she was committed to "honesty and integrity" [9]. The nurse suggested that patient care was compromised due to the parties involved prioritizing their military careers. The nurse's statements about themselves were aligned with justice.

\subsection{Criticisms of Kohlberg's Theory and the Usefulness of Gilligan's Theory}

Various authors support Gilligan's theory over Kohlberg's theory (Table 4). Chally [10] indicated that difficult moral decisions are being made every day in the field, and stressed the importance of understanding the decision making perspective of nurses. As suggested by Chally (1990b), nurses are concerned with both justice and caring. To understand moral decision making, all perspectives must be explored as possible frameworks for the deliberation of moral dilemmas [10].

Moreover, from interviews with NICU nurses, Chally 
Table 4. Opinion of about the utility of the Gilligan theory in the analysis of the moral conflict of the nurse.

\begin{tabular}{|c|c|}
\hline Author & Summary of opinion \\
\hline $\begin{array}{l}\text { Chally, P.S. } \\
\text { (1992) }\end{array}$ & $\begin{array}{l}\text { Background of the study } \\
\text { - As suggested by Chally (1990b), nurses are concerned with both justice and caring. To understand moral decision making, } \\
\text { all perspectives must be explored as possible frameworks for the deliberation of moral dilemmas.(p.475) } \\
\text { Discussion } \\
\text { - The study lends credence to two of Gilligan's }(1997,1982) \text { developmental levels. (p.478) } \\
\text { - } \quad \text { All of the categories if care identified in the study, except caring for self, could be included in the level of goodness as } \\
\text { - } \quad \text { self-sacrifice. The morality of nonviolence stresses the equality of self and others. (p.478) } \\
\text { - } \quad \text { Thesults of this study provide validation for three of Kohlberg's stages of moral development. (p.479) } \\
\text { role category of the justice perspective. Kohlberg's social system morality stage was suggested by nurses whose justice } \\
\text { perspective was based on legal issues, rights, rules, and obligations and commitments. } \\
\text { Kohlberg's social contract morality stage was supported by nurses who described societal concerns. (p479) } \\
\text { Conclusions } \\
\text { - Results of the study suggest that attempt to describe nurses' moral development must go beyond Kohlberg's (1978, 1985) } \\
\text { theory of justice as a moral perspective and include Gilligan's(1987) theory of care as a moral perspective. (p.480) } \\
\text { - Most tolls concerning moral development used in nursing research are based on Kohlberg's (1971, 1976, 1978) theory. (p.481) } \\
\text { The continued use of tools developed solely on the justice perspectives seems questionable. (p.481) }\end{array}$ \\
\hline $\begin{array}{l}\text { Chally, P.S. } \\
\text { (1995) }\end{array}$ & $\begin{array}{l}\text { Conceptual framework } \\
\text { - Recently, nurses have become interested in Gilligan's }(1982,1987) \text { work on moral development, which describes moral decision } \\
\text { making from a perspective of care. The care perspective is described as one of connection, interrelatedness, and attachment } \\
\text { among people. Choices are made because of understanding the uniqueness of the situation and connections between people. } \\
\text { Principles are not necessarily applied impartially to situations because the uniqueness of each circumstance precludes such } \\
\text { detachment.(p.120) } \\
\text { Discussion } \\
\text { Exposure to more than one perspective of moral decision making, may result in identification of alternatives to moral issues } \\
\text { that would have not been obvious with the use of only one perspective (Chally, 1992). (p.123) } \\
\text { All subjects, nurses working in both neonatal and adult intensive care, discussed both perspectives when describing a moral } \\
\text { dilemma that they had experienced in professional practice. The care and justice taxonomies remained valid for the nurses' } \\
\text { discussions of dilemmas.(p.123) }\end{array}$ \\
\hline $\begin{array}{l}\text { Millette, B.E. } \\
\text { (1994.) }\end{array}$ & $\begin{array}{l}\text { Background of the study } \\
\text { - Several authors (Cooper, 1989, 1993; Nokes, 1989; Parker, 1990a, 1990b) suggest that Gilligan's (1997, 1979, 1981, 1982a, } \\
\text { 1982b) approach has real value when applied to nursing, especially when trying to understand how nurses move through the } \\
\text { murky waters of moral decision making. As Cooper (1989) phases it, Gilligan "has provided a framework ... for holding fast } \\
\text { to caring concerns in the face of the indifference of the scientific context in which much of nursing occurs”. (p.662) } \\
\text { - Gilligan (1977, 1979, 1981, 1982a, 1982b) does not say that either perspective is better but that they are different approaches to } \\
\text { solving dilemmas. Nor does she contend that caring is an exclusively feminine perspective. The caring orientation does, } \\
\text { however, clarify and explicate some of the situations that women, and especially nurses, have experienced in their lives. } \\
\text { (p.662-663) } \\
\text { The orientation merely guides the exploration of the subject's approach and eventual solution to a problem. They contend } \\
\text { that the care and justice orientations can be evident in the same story. (p.663) } \\
\text { Gilligan (1977) believes that the individual's process and reasoning can be best understood when the person describes a } \\
\text { personal experience. This approach directs the researcher to ask the subject to describe a moral situation in which there is a } \\
\text { moral choice, and then to define and explore the personally experienced moral situation.(p.663) } \\
\text { Conclusions } \\
\text { Both the caring and the justice orientation are present in the nurses' stories in this study. Neither orientation seems to be more } \\
\text { effective in assisting nurses in making moral choices. Both orientations guide nurses in the provision of quality care and toward } \\
\text { a role in client advocacy. (p.672) }\end{array}$ \\
\hline
\end{tabular}

[10] confirmed that care and justice perspectives exist in moral conflict, and considered these by fitting them to Gilligan's and Kohlberg's stages of moral development. The care categories of not hurting, welfare of others, attachment and connection, appreciation of differences, and care of self were fitted to Gilligan's stages of moral development. Categories other than care of self were included in the second stage (goodness as self-sacrifice), and care of self was included in the third stage (morality of non-violence). The justice categories of legal issues, rights, rules, obligations and commitments, societal concerns, and roles were fitted to Kohlberg's stages of moral development. Roles was included in Stage 3 (interper- sonal morality), legal issues, rights, rules, and obligations and commitments were included in Stage 4 (morality of social systems), and societal concerns was included in Stage 5 (morality of social contracts). Moreover, Chally [10] suggested that attempts to describe nurses' moral development must go beyond Kohlberg's theory of justice as a moral perspective and include Gilligan’s theory of care as a moral perspective. Most tools concerning moral development used in nursing research are based on Kohlberg's theory. These tools were developed under the assumption that all people strive to deliberate dilemmas from the justice perspective. Because this study offers evidence that not all nurses deliberate moral dilemmas 
from the justice perspective, the continued use of tools developed solely on the justice perspective seems questionable [10].

Chally [11] stated that nurses have become interested in Gilligan's work on moral development, which describes moral decision making from a perspective of care. The care perspective is described as one of connection, interrelatedness, and attachment among people. Choices are made because of understanding the uniqueness of the situation and connections between people. Principles are not necessarily applied impartially to situations because the uniqueness of each circumstance precludes such detachment [11].

Chally [11] further suggested that exposure to more than one perspective of moral decision making may result in identification of alternatives to moral issues that would have not been obvious with use of only one perspective. Moreover, because all subjects, nurses working in both neonatal and adult intensive care, discussed both perspectives when describing a moral dilemma that they had experienced in professional practice, the care and justice taxonomies remained valid for the nurses' discussions of dilemmas [11].

According to Millette [9], several authors (Cooper, 1989; Nokes, 1989; Parker, 1990a, 1990b) suggest that Gilligan's approach has real value when applied to nursing, especially when trying to understand how nurses move through the murky waters of moral decision making.

Moreover, Millette [9] noted Gilligan does not say that either perspective is better but that they are different approaches to solving dilemmas, she contended that caring is an exclusively feminine perspective. Based on this, Millette [9] stated that the care orientation does, however clarify and explicate some of the situations that women, and especially nurses, have experienced in their lives. In complex moral decision making, Gilligan's approach is useful for understanding nurse behavior. Gilligan's care and justice become perspectives for addressing moral dilemmas which guide the subjects' approach and the final problem resolution.

Millette [9] stated that Gilligan believes that moral decisions are "insistently contextual" and that the individual's process and reasoning can be best understood when the person describes a personal experience. This approach directs the researcher to ask the subject to describes a moral situation in which there is a moral choice, and then to define and explore the personally experienced moral situation [9].

\section{DISCUSSION}

\subsection{Characteristics of Care and Justice in Moral Conflicts Experienced by Nurses}

Our analysis confirmed that care is a perspective held by all nurses. Chally's [10] care categories were borne from occupational moral conflicts and are suggestive of the care orientation of nurses. These care categories were fitted to Gilligan's three stages of moral development. While the first stage relates to self-centered judgments, the second stage involves empathy for others, and the third stage involves care of self while considering relationships with others. Gilligan's model considers the obligation of avoiding hurting others in relationships a responsibility, and that having responsibility and empathy toward self and others allows for moving to the next stage. Chally's [10] care categories are included in Gilligan's second stage, i.e., having empathy for others or for others and self, and the care orientation of nurses is placed at an even higher stage. Moreover, among Chally's $[10,11]$ care categories, attachment and connection is particularly important. Even Millette's [9] representative case for the caring orientation referred to relationships and connections with others. Nursing comes into effect based on the relationship between the one caring and the one cared for. Consistent with this, Noddings [3] noted that to care is to be in a burdened mental state, one of anxiety, fear or solicitude about something or someone. Moreover, regarding the provision of care, Noddings [3] stated that I care for someone if I feel a stir of desire or inclination toward him, I care for someone if I have regard for his views and interests, I have the care of an elderly relative if I am charged with the responsibility for his physical welfare. In other words, through the relationship with one cared for emerges emotions for and an understanding toward that individual, translating into caring behavior. Thus, attachment and connection in a patient-nurse relationship can be considered essential elements of nursing.

Chally [11] considered care of self to be the major theme of nursing. In Gilligan's model, this category is placed in the highest stage. Nurses experience substantial stress in the clinical setting, which can lead to burnout. Thus, reducing their stress and maintaining their mental and physical health are important. Mayeroff [12] viewed care mainly from the perspective of the person providing care, and stated that to care for another person, in the most significant sense, is to help him grow and actualize himself. Nurses develop as humans through continued nursing, and it is important that they confirm their own development and approve themselves via nursing. Thus, nurses must both manage their stress and approve themselves simultaneously.

Justice was not a perspective shared by all nurses in moral conflict situations. Yet, depending on the particular conflict, nurses made decisions in accordance with justice, which is just as important as care. Chally [10] also fitted her justice categories to Kohlberg's stages of moral development, which consist of three levels and six 
hierarchical stages. The stages proceed in the following order: stages I and II relate to self-centered views, stages III and IV to interpersonal relationships and social views that support the community, and stages V and VI to universal views based on social values. Among the six justice categories described by Chally [10], "roles" is included in stage III, whereas the remaining categories are included in stage IV or V. The justice orientation is based in interpersonal relationships, judgments that support groups, or judgments within the social system, and belongs to an even higher stage of development. Moreover, the category of "roles" also suggested problems regarding the inequality between physicians and nurses. Both physicians and nurses have specialized roles; a physician provides medical treatment, whereas the nurse provides living assistance. Given these roles, nurses spend considerably more time with patients than physicians. This leads to a stronger feeling of "attachment and connection" toward patients, and can lead to a situation in which they fail to understand the roles of other professionals. The same can occur regarding a patient's future-unlike physicians, who make treatment decisions, nurses think from a perspective that emerges from an understanding of the patient/family's wishes obtained during the course of living assistance. This leads to a stronger feeling of role inequality with physicians. The moral conflict in roles is thought to arise from the existence of attachment and connection, an important element of nursing. It is important for nurses to have a moral perspective that does not overemphasize either category.

Similar to Chally's [11] view that nurses must understand the experiences of physicians, nurse/physician collaborations represent an important issue. Moreover, lack of power was a major theme in conflicts regarding the justice perspective for nurses. In Millette's [9] a mostly justice orientation narrative, the nurse could not resolve the problem through the formal chain of command, and the problem was resolved through an informal network. Since nurses cannot act through proper channels in an organization, it is possible that they would be held personally accountable when a problem worsens. Thus, the lack of power among nurses can cause moral conflicts and influence decision making.

\subsection{Applying Gilligan's Theory to Studies That Target Nurses}

According to the three studies described herein, since people use both care and justice perspectives in times of moral conflict, it is inappropriate to use Kohlberg's theory, which is based solely on the justice perspective, in research relating to moral development. Instead, it is more appropriate to use Gilligan's theory, which is based on both care and justice perspectives. Gilligan considers the care orientation that emphasizes interpersonal relationships and connections to be an exclusively feminine perspective. Millette [9] indicated that nurse groups are predominantly female and thus the caring orientation is characteristic of nurses - therefore, the caring orientation can be used to clarify their experiences. According to the US Bureau of Labor Statistics, there were 164,000 active male nurses in 2002, which corresponds to a $71 \%$ increase over 20 years, with male nurses comprising only about $6 \%$ of the entire nursing population [13]. According to the Japanese Nursing Association, male nurses comprised about 3\% of the Japanese nursing population in 2000, and only increased to 5\% eight years later [14]. While the nursing profession has never been solely a female profession, the number of male nurses remains low. Consistent with Millette's [9] interpretation, nurses remain a group with predominantly feminine views. Given that all nurses expressed the care category in Chally's [11] study, care orientation is considered important for nurses' decision making. However, nurses may overly focus on relationships and connections with their patients, and their decision making tends to be influenced by personal relationships and emotions. In order to fairly judge moral problems, the justice perspective, which judges a situation with universal rules, is essential. Accordingly, both care and justice perspectives are essential and are useful for understanding and analyzing moral conflicts experienced by nurses.

\section{CONCLUSION}

In the present literature analysis, we found that care and justice coexist in the moral perspective of nurses. Attachment and connections based on relationships with patients are essential elements of care, and self-care is important in moral decision making. The inequality between nurse and physician roles was an issue raised with the justice perspective. Since nurses' roles are strongly influenced by their affection toward and connections with their patients, it is important not to overemphasize either perspective. Given the importance of care and justice perspectives in moral reasoning, Gilligan's theory, which incorporates both perspectives, is useful for analyzing moral reasoning in nurses.

\section{REFERENCES}

[1] Gilligan, C. (1982) In a different voice. Harvard University Press, Harvard.

[2] Kuhse, H. (1997) Caring: Nurses, women and ethics. Blackwell Publishers Ltd., London.

[3] Noddings, N. (1984) Caring. University of California Press Ltd., Berkeley.

[4] Chally, P.S. (1990) Moral and ethical development research in nursing education. National League for Nursing, 
15-2339, 33-47.

[5] Goethals, S., Gastmans, C. and de Casterlé, B.D. (2010). Nurses' ethical reasoning and behavior: A literature review. International Journal of Nursing Studies, 47, 635650. http://dx.doi.org/10.1016/j.ijnurstu.2009.12.010

[6] Chally, P.S. (1990) Theory derivation in moral development. Nursing \& Health Care, 11, 302-306.

[7] Casterlé, B.D., Roelens, A. and Gastmans, C. (1998) An adjusted version of Kohlberg's moral theory: Discussion of its validity for research in nursing ethics. Journal of Advanced Nursing, 27, 829-835. http://dx.doi.org/10.1046/j.1365-2648.1998.00597.x

[8] Millette, B.E. (1993) Client advocacy and the moral orientation of nurses. Western Journal of Nursing Research, 15, 607-618. http://dx.doi.org/10.1177/019394599301500507

[9] Millette, B.E. (1994) Using Gilligan’s framework to analyze nurses' stories of moral choices. Western Journal of Nursing Research, 6, 660-674. http://dx.doi.org/10.1177/019394599401600605

[10] Chally, P.S. (1992) Moral decision making in neonatal intensive care. Journal Obstetric Gynecologic Neonatal Nursing, 21, 475-482. http://dx.doi.org/10.1111/j.1552-6909.1992.tb01768.x

[11] Chally, P.S. (1995) Nursing research: Moral decision making by nurses in intensive care. Plastic Surgical Nursing, 15, 120-124.

[12] Mayeroff, M. (1971) On caring. Harper Perennial, New York.

[13] Anne, B.E. (2007) Men at work: Male nurses hit the road. Modern Medicine, 1 April 1971, 1-5.

http://healthcaretraveler.modernmedicine.com/healthcaretraveler/news/modernmedicine/modern-medicine-feature -articles/men-work-male-nurses-hit-ro

[14] Japanese Nursing Association Publishing Company (2012) Statistical data on nursing service in Japan. http://www.nurse.or.jp/home/publication/toukei/pdf/touke i05.pdf

[15] Casterlé, B.D., Izumi, S., Godfrey, N.S. and Denhaerynck, D. (2008) Nurses' responses to ethical dilemmas in nursing practice: Meta-analysis. Journal of Advanced Nursing, 63, 540-549. http://dx.doi.org/10.1111/j.1365-2648.2008.04702.x

[16] Susan, L. (2003) The experience of being an older staff nurse. Western Journal of Nursing Research, 25, 45-56. http://dx.doi.org/10.1177/0193945902238835

[17] Pinch, W.J. and Mary, E.P. (1997) Moral orientation of elderly persons: Considering ethical dilemmas in health care. Nursing Ethics, 4, 380-393. 